\title{
Serological Comparison of Bovine T-mycoplasmas
}

\author{
By C. J. HOWARD AND R. N. GOURLAY \\ Agricultural Research Council, Institute for Research on Animal Diseases, \\ Compton, Newbury, Berkshire \\ (Received 3 May 1973)
}

\begin{abstract}
SUMMAR Y
Eight bovine T-mycoplasmas examined serologically by the metabolism inhibition test, growth inhibition on agar and by immunofluorescence showed considerable serological heterogeneity. None of the eight strains was serologically identical with any other, but three formed a group of similar organisms. No evidence was obtained for one particular serotype being confined to a specific anatomical site or being isolated typically from any particular pathological condition. Antisera to the bovine T-mycoplasmas were tested against eight serologically distinct human strains and a caprine, a simian and a canine T-mycoplasma. None of the non-bovine strains was identical to these bovine T-mycoplasmas.
\end{abstract}

\section{INTRODUCTION}

Most studies on the serology of human T-mycoplasmas have been made with the metabolism inhibition test (Purcell, Taylor-Robinson, Wong \& Chanock, 1966) and these have demonstrated the serological diversity of this group of micro-organisms (Purcell et al. 1967). No correlation between serotype and anatomical site of colonization, or serotype and isolation from pathological conditions or normal subjects, has been found (Ford, I967; Purcell, Chanock \& Taylor-Robinson, 1969). Lin, Kendrick \& Kass (1972) examined human T-mycoplasma strains using a complement-dependent mycoplasmacidal test and came to the same conclusions.

Black (197I) examined human T-mycoplasmas by three additional serological tests - growth inhibition on agar, immunofluorescence, and indirect haemagglutination. On the basis of his results he postulated that at least seven distinct serotypes of human T-mycoplasmas exist.

Preliminary examinations of the serology of bovine T-mycoplasmas have been made with only the metabolism inhibition test. These studies have indicated that bovine strains are also serologically heterogeneous (Taylor-Robinson, Thomas \& Dawson, 1969; Howard \& Gourlay, 1972).

We have now examined the antigenic structure of bovine T-mycoplasmas using three serological methods, to provide a basis from which further studies on the pathogenicity of the group can be made.

\section{METHODS}

T-mycoplasma strains. Strains isolated from cattle and against which antisera were raised are listed in Table I. Strains were purified by filtration of broth cultures through $450 \mathrm{~nm}$ Millipore filters and propagation of single colonies, on three successive occasions, as recommended by the Sub-committee on the Taxonomy of Mycoplasmatales (1972). Strains Bu2 and F80I were isolated from the urogenital tract of cattle and strain oI 3 originated from 
the eye of a cow with kerato-conjunctivitis. The other strains (A4I7, Gra383, D48, vic9 and Mmbi43) were isolated from pneumonic calf lungs.

The human T-mycoplasma strains 7, 23, 27, 58, 354, Pirillo, Cook and T960 were provided by Dr F. T. Black (Aarhus, Denmark). All except T 960 have been examined by him and proposed as seven distinct serotypes of human T-mycoplasmas (Black, 197I).

Canine strain spizor and simian strain spi625A were obtained from Dr D. TaylorRobinson (M.R.C. Clinical Research Centre, Northwick Park, London) and have been described by him (Taylor-Robinson, Martin-Bourgon, Watanabe \& Addey, 197I). The caprine T-mycoplasma strain GI was isolated from the urogenital tract of a goat (Gourlay, Brownlie \& Howard, I973).

Media. The liquid medium used was U2 broth (Howard \& Gourlay, 1973). Solid medium was made according to Gourlay et al. (1973).

Serological tests. The metabolism inhibition test of Purcell et al. (I966) was performed according to Howard \& Gourlay (1973). Guinea-pig serum was not added to the system.

The ability of antisera to inhibit the growth of strains on solid media was examined in a similar manner to that of Black (I97I). Solid medium was inoculated with a $20 \mu 1$ drop of broth culture; a well, $1.5 \mathrm{~mm}$ in diameter, was then cut in the agar in the centre of the drop and filled with antiserum. Plates were incubated for three days at $37^{\circ} \mathrm{C}$ under $5 \%(\mathrm{v} / \mathrm{v})$ $\mathrm{CO}_{2}$ in $\mathrm{N}_{2}$. Zones of inhibition of growth were measured under a microscope with $\times 40$ magnification.

Strains were examined by the indirect immunofluorescent technique for unfixed mycoplasma colonies according to Rosendal \& Black (1972) with antisera raised in rabbits and conjugated goat or pig anti-rabbit sera (Nordic Diagnostics, Fraburg Ltd, Maidenhead, Berkshire).

The schedule used for the preparation of antisera in New Zealand white rabbits to T-mycoplasma strains grown in $\mathrm{U}_{2}$ broth was as previously stated (Howard \& Gourlay, I972). All antisera were stored at $-20^{\circ} \mathrm{C}$ and heated at $56{ }^{\circ} \mathrm{C}$ for $30 \mathrm{~min}$ before use.

\section{RESULTS}

Comparison of bovine T-mycoplasmas by the metabolism inhibition test. The titres of antisera to eight bovine T-mycoplasmas were measured against the same eight strains by the metabolism inhibition test (Table I). High titres were obtained with homologous antisera. None of the strains was identical with any other, but strains A4I7, F80I and Gra383 appeared to be similar. The other five strains were distinct from each other and from the group A4I7, F80I and Gra383. Because a normal rabbit serum titre of 20 in the metabolism inhibition test with bovine T-mycoplasmas has been reported (Howard \& Gourlay, I973), titres of 20 were ignored. Antisera did have low titres to some heterologous strains suggesting some degree of relatedness between distinguishable strains (Table I).

Comparison of bovine T-mycoplasmas by growth inhibition on agar. When strains were compared by this method essentially the same result was found as with the metabolism inhibition test (Table 2). The three strains A4I7, F80I and Gra3 83 formed a group of similar but not identical isolates. The most obvious difference between these strains was the inability of antiserum to strain Gra383 to inhibit the growth on agar of strain A417. The other five strains were distinct from this group and from each other.

Comparison of bovine T-mycoplasmas by immunoftuorescence. This method (Table 3) gave a similar result to the metabolic and growth inhibition tests, the only difference being the detection of antibody to strain vic9 in antisera to D48. 
Table I. Relation between bovine T-mycoplasma strains measured by the metabolism inhibition test

\begin{tabular}{|c|c|c|c|c|c|c|c|c|}
\hline \multirow[b]{2}{*}{ Strain } & \multicolumn{8}{|c|}{ Titre $^{*}$ with antisera to } \\
\hline & A4 47 & F80 I & Gra 383 & D48 & vic9 & 013 & BU2 & Mmb I 43 \\
\hline A4 17 & $>20480$ & 10240 & 160 & 20 & $<20$ & $<20$ & 20 & $<20$ \\
\hline $\mathrm{F} 80 \mathrm{I}$ & 320 & $>20480$ & 5120 & I 60 & $<20$ & $<20$ & 160 & 40 \\
\hline Gra 383 & 640 & $>20480$ & 10240 & 80 & $<20$ & 40 & 160 & 160 \\
\hline D4 8 & 40 & 20 & $<20$ & $>20480$ & 20 & 20 & $<20$ & $<20$ \\
\hline vic9 & 40 & 80 & 20 & 160 & $>20480$ & 40 & 20 & $<20$ \\
\hline O I 3 & 40 & 20 & $<20$ & 20 & 20 & $>20480$ & 20 & 40 \\
\hline Bu2 & 160 & 83 & 80 & 40 & 20 & 80 & $>20480$ & 40 \\
\hline Mmb I 43 & 40 & 20 & 20 & 40 & 40 & 40 & 20 & $>20480$ \\
\hline
\end{tabular}

* Reciprocal of the highest dilution of antiserum that inhibited breakdown of urea during growth.

Table 2. Relation between bovine T-mycoplasma strains measured by growth inhibition by antisera

Zone* of inhibition of growth by antisera to

$\begin{array}{lcccccccc}\text { Strain } & \text { A417 } & \text { F80I } & \text { Gra383 } & \text { D48 } & \text { vic9 } & \text { OI3 } & \text { Bu2 } & \text { Mmbi43 } \\ \text { A417 } & 7 & 6 & 0 & 0 & 0 & 0 & 0 & 0 \\ \text { F801 } & 4 & 6 & 4 & 0 & 0 & 0 & 0 & 0 \\ \text { Gra383 } & 4 & 6 & 4 & 0 & 0 & 0 & 0 & 0 \\ \text { D48 } & 0 & 0 & 0 & 8 & 0 & 0 & 0 & 0 \\ \text { vic9 } & 0 & 0 & 0 & 0 & 7 & 0 & 0 & 0 \\ \text { OI3 } & 0 & 0 & 0 & 0 & 0 & 8 & 0 & 0 \\ \text { Bu2 } & 0 & 0 & 0 & 0 & 0 & 0 & 7 & 0 \\ \text { Mmbi43 } & 0 & 0 & 0 & 0 & 0 & 0 & 0 & 4\end{array}$

* Figures indicate diameter, in $\mathrm{mm}$, of zones of inhibition of growth of organisms by antiserum on solid medium. Incubation period three days.

Table 3. Relation between bovine T-mycoplasma strains measured by indirect immunofluorescence

Titre* with antisera to

$\begin{array}{lrrrrrrrr}\text { Strain } & \text { A4I7 } & \text { F8OI } & \text { Gra383 } & \text { D48 } & \text { vic9 } & \text { OI3 } & \text { BU2 } & \text { Mmb I43 } \\ \text { A4I7 } & 160 & 160 & 80 & <5 & <5 & <5 & <5 & <5 \\ \text { F8OI } & 160 & 160 & 40 & <5 & <5 & <5 & <5 & 5 \\ \text { Gra383 } & 80 & 80 & 80 & <5 & <5 & <5 & <5 & <5 \\ \text { D48 } & 5 & <5 & <5 & 160 & 5 & 5 & 5 & <5 \\ \text { vic9 } & <5 & <5 & <5 & 80 & 80 & 10 & <5 & <5 \\ \text { O13 } & <5 & <5 & <5 & 5 & 5 & 80 & <5 & <5 \\ \text { Bu2 } & <5 & <5 & <5 & <5 & <5 & <5 & 320 & <5 \\ \text { Mmbi43 } & <5 & <5 & 5 & <5 & <5 & <5 & <5 & 320\end{array}$

* Reciprocal of the highest dilution of rabbit antiserum resulting in fluorescence of colonies on agar after addition of fluorescein-conjugated anti-rabbit serum.

Relation between T-mycoplasma strains isolated from different animal species measured by the metabolism and growth inhibition tests. None of the antisera raised against bovine T-mycoplasmas had high titres against human strains by the metabolism inhibition test (Table 4). Some of the antisera had low titres to the human strains, the highest being a titre of 320 of antiserum to bovine strain Buz against human strain 27. 
Table 4. Metabolism inhibition titre of antisera to bovine T-mycoplasmas tested against human T-mycoplasmas

\begin{tabular}{|c|c|c|c|c|c|c|c|c|}
\hline \multirow{2}{*}{$\begin{array}{c}\text { Human } \\
\text { T-mycoplasma } \\
\text { strain }\end{array}$} & \multicolumn{8}{|c|}{ Titre* with antiserum to bovine strain } \\
\hline & A4 17 & F8OI & Gra383 & D48 & vic9 & 013 & Bu2 & Mmbi43 \\
\hline 7 & $<20$ & 80 & $<20$ & 20 & $<20$ & $<20$ & $<20$ & $<20$ \\
\hline 23 & 40 & 40 & $<20$ & 20 & $<20$ & $<20$ & 20 & 40 \\
\hline 27 & $<20$ & 160 & $<20$ & $<20$ & $<20$ & 40 & 320 & $<20$ \\
\hline 58 & $<20$ & $<20$ & $<20$ & $<20$ & $<20$ & $<20$ & $<20$ & $<20$ \\
\hline 354 & $<20$ & $<20$ & $<20$ & $<20$ & $<20$ & 40 & $<20$ & $<20$ \\
\hline Pirillo & $<20$ & 20 & $<20$ & $<20$ & $<20$ & 20 & $<20$ & $<20$ \\
\hline Cook & $<20$ & $<20$ & $<20$ & $<20$ & $<20$ & $<20$ & 20 & $<20$ \\
\hline T960 & $<20$ & $<20$ & $<20$ & $<20$ & $<20$ & $<20$ & $<20$ & $<20$ \\
\hline
\end{tabular}

* Reciprocal of the highest dilution of antiserum that inhibited breakdown of urea during growth.

When the same anti-bovine T-mycoplasma sera were examined for their ability to inhibit the growth on agar of the same eight human strains and also of simian, canine and caprine T-mycoplasmas, no zones of inhibition were observed. Thus none of the non-bovine strains examined was found to be serologically the same as the bovine strains.

Ability to identify other bovine strains. A further 27 bovine strains were examined by the metabolism inhibition test with the eight available antisera. Eleven of these strains could be serotyped, i.e. high titres were obtained when the eight antisera were tested against them. Four strains isolated from lungs were serologically similar to strain 013 which was isolated from the eye of a cow. Serologically similar strains were also isolated from the lungs and urogenital tract of cattle.

\section{DISCUSSION}

The three serological tests gave essentially the same, but not identical, results. Since these tests vary in their sensitivity, the metabolism inhibition test being the most sensitive and growth inhibition on agar the least sensitive (Taylor-Robinson, I968), some divergence of the results obtained with the different methods is to be expected. However, the finding that shared antigens were not detected by all the tests cannot be explained in terms of the sensitivity of the tests alone. Antibody to strain A4I 7 was demonstrated in antiserum to strain Gra3 83 by immunofluorescence and at a low titre by metabolism inhibition, but it was not demonstrated by growth inhibition. Similarly, antibody to vic9 was demonstrated in antiserum to strain $\mathrm{D} 48$ by immunofluorescence and to a lesser extent by metabolism inhibition, but not by growth inhibition on agar. The three strains A4I7, Gra383 and F80I are similar and can perhaps be grouped together. Strains vic9 and D48 also appear to share a common antigen but only a one-way cross-reaction was demonstrated. The other three strains are distinct from each other and from the five already mentioned. The low metabolism inhibition titres of antisera, when tested against heterologous bovine strains, indicate the existence of common shared antigens besides those antigens by which the strains are distinguished. The finding that the three strains A4I7, F80I and Gra383 form a similar but not identical group indicates that amongst bovine T-mycoplasmas, groups of similar but not identical organisms exist. This is analogous to the serologically similar but not identical strains amongst the species of Mycoplasma pulmonis (Forshaw \& Fallon, 1972). These results may indicate a system by which the bovine T-mycoplasmas could be classified, perhaps with groups of similar organisms being given the status of species or subspecies. 
As a group, bovine T-mycoplasmas are serologically heterogeneous. Strains which possess common antigens have been isolated from different anatomical sites of cattle, and we have no evidence for any serotype being confined to a particular organ or being associated with any particular pathological condition. The same situation occurs in man in that human T-mycoplasma strains are serologically heterogeneous and no serotype is characteristically isolated from any one anatomical site or disease (Ford, 1967; Purcell et al. 1969; Lin et al. 1972). Studies on the virulence of bovine T-mycoplasma strains have not been extensive enough to say whether or not any particular serotype is characteristically virulent or avirulent. However, serologically distinct strains have been shown to be virulent for the bovine udder (Howard, Gourlay \& Brownlie, I973).

Of the further 27 bovine T-mycoplasmas examined by the metabolism inhibition test, I I $(40 \%)$ could be serotyped. Clearly many other serotypes of bovine T-mycoplasmas must exist besides those encountered here.

None of the human, canine, simian or caprine strains examined was serologically the same as any of the bovine strains. However, the low metabolism inhibition titres observed when antisera to bovine strains were tested against human strains presumably indicates some shared antigens; these must be distinct from the major antigens which distinguish the bovine serotypes. Low metabolism inhibition titres of antisera to strains isolated from one animal species have been observed when tested against strains isolated from other animal species (Taylor-Robinson et al. I97I ; Howard \& Gourlay, 1973).

The T-mycoplasmas isolated from different animal species appear no more different serologically from each other than are some strains from the same animal species. Serologically identical strains from different animal species have so far not been isolated.

We would like to thank Miss J. Wren for excellent technical assistance.

\section{REFERENCES}

BLACK, F. T. (I97I). Serological methods for classification of human T-mycoplasmas. In $V$. Internationaler Kongress Für Infektionskrankheiten, Vienna, 197o. Vol. I. Virus: Mycoplasma and L Forms etc., pp. 4074I I. Vienna: Wiener Medizinische Akademie.

FORD, D. K. (1967). Relationships between mycoplasma and the aetiology of nongonococcal urethritis and Reiter's syndrome. Annals of the New York Academy of Sciences 143, $50 \mathrm{I}-504$.

Forshaw, K. A. \& Fallon, R. J. (1972). Serological heterogeneity of Mycoplasma pulmonis. Journal of General Microbiology 72, 50I-5IO.

Gourlay, R. N., Brownlie, J. \& Howard, C. J. (I973). Isolation of T-mycoplasmas from goats, and the production of sub-clinical mastitis in goats by the intramammary inoculation of human $\mathrm{T}$-mycoplasmas. Journal of General Microbiology 76, 25I-254.

Howard, C. J. \& Gourlay, R. N. (1972). Serology of bovine T-mycoplasmas. British Veterinary Journal 128, xxxvii-xi.

Howard, C. J. \& Gourlay, R. N. (1973). Inhibition by normal rabbit serum of the growth of T-mycoplasma strains isolated from different animal species. Journal of General Microbiology 78, 277-284.

Howard, C. J., Gourlay, R. N. \& Brownlie, J. (1973). The virulence of T-mycoplasmas, isolated from various animal species, assayed by intramammary inoculation in cattle. Journal of Hygiene 71, $163-170$.

LrN, J. S. L., KENDrick, M. I. \& KASs, E. H. ( I972). Serologic typing of human genital T-mycoplasmas by a complement-dependent mycoplasmacidal test. Journal of Infectious Diseases 126, 658-663.

Purcell, R. H., Chanock, R. M. \& Taylor-Robinson, D. (1969). Serology of the mycoplasmas of man. In The Mycoplasmatales and the L-phase of Bacteria, pp. 22 I-264. Edited by L. Hayflick. Amsterdam: North-Holland Publishing Co.

Purcell, R. H., Taylor-Robinson, D., Wong, D. \& Chanock, R. M. (1966). Color test for the measurement of antibody to T-strain mycoplasmas. Journal of Bacteriology 92, 6-1 2. 
Purcell, R. H., Wong, D., Chanock, R. M., TAYlor-Robinson, D., Canchola, J. \& Valdesuso, J. (1967) Significance of antibody to mycoplasma as measured by metabolic-inhibition techniques. Annals of the New York Academy of Sciences 143, 664-675.

Rosendal, S. \& BLACK, F. T. (1972). Direct and indirect immunofluorescence of unfixed and fixed mycoplasma colonies. Acta pathologica et microbiologica scandinavica B 80, 6I 5-622.

Subcommittee ON the Taxovomy of Mycoplasmatales (1972). Proposal for minimal standards for description of new species of the order Mycoplasmatales. International Journal of Systematic Bacteriology 22, $184-188$.

TAYLoR-Robinson, D. (I968). The biology of mycoplasmas. Journal of Clinical Pathology 21, S2, 38-5I.

TAylor-Robinson, D., Martin-Bourgon, C., Watanabe, T. \& Addey, J. P. (1971). Isolation of T-mycoplasmas from dogs and squirrel monkeys: biological and serological comparison with those isolated from man and cattle. Journal of General Microbiology 68, 97-107.

TAYlor-Robinson, D., Thomas, M. \& Dawson, P. L. (1969). The isolation of T-mycoplasmas from the urogenital tract of bulls. Journal of Medical Microbiology 2, 527-533. 